\title{
TORAJAN LIVELIHOODS: THE CULTURAL DYNAMICS OF ECONOMIC LIFE
}

Theory is something to do, not simply to read. The theoretical resources available to today's sociologists are enormous, but this doesn't mean that theoretical work can stop. ${ }^{1}$

In the introductory chapter, I observed that standard livelihood analyses appear to be of limited help in understanding the full complexities of everyday Torajan life. Although these models have improved the analysis of livelihoods by paying greater attention to individual agency, their formulation is still primarily based on the economy while the remaining (political, cultural, and religious) aspects are seen merely as context. Academics in the field of livelihoods have tried to integrate the social dimension by adding concepts such as social capital to their model but, as the term suggests, these are strongly translated into economic terms. The question is whether the emphasis should not be more on making a living, or a decent living, something that includes more than simply income or capital accumulation practices. In Geertz's words (1980), we should not look for the 'political' based on what we find in our own country; instead we should elaborate a 'poetics of life' by identifying relevant Torajan emotions and construing their actions in their own contexts. In so doing, what first appears to be a theatrical piece may later become real and as imagined as the imaginary. From this perspective, we should try to understand the whole 'Torajan theatre show' which embraces just as much struggles for power and status, symbolic expressions and social manifestations, as it does income accumulating activities.

In this chapter, I add a broad spectrum of concepts and analytical approaches to the livelihoods perspective that will better enable us to come to terms with Torajan livelihoods. As Hefner (1990) already noted in his account on the political economy of mountain Java in which he attempts to understand a Southeast Asian peasantry's experience of politics and economic change and the practical circumstances that

\footnotetext{
${ }^{1}$ Calhoun quoted in: Calhoun, Gerteis, Moody, Pfaff and Virk 2002:19.
}

(C) EDWIN DE JONG, 2013 | DOI 10.1163/9789004252479_003

This is an open access chapter distributed under the terms of the CC-BY-NC-ND License. 
have constrained that peasantry's economic actions and conditioned its awareness: 'In recent years, a number of authors have commented that the study of political-economic change requires a new style of "middle-range" analysis.' To develop such an analysis, Hefner attempted to synthesize economic anthropology with a wider culturalist approach. While reasoning more or less in the same way as Hefner 'through a dialectical tacking between activity and constraint', in developing a new style of 'middlerange analysis' I will adopt a kind of 'practice theory' that includes concepts and approaches that stem from a variety of disciplines, such as development studies, cultural anthropology, sociology, economics and human geography. The attempt to put together several elements from these various disciplines should not be seen as a 'game of trial and error'. Rather, it is an attempt to construct a profound theoretical framework for the analysis of the complex empirical reality I encountered during my fieldwork, and in so doing the aim is to contribute to the theoretical discussion within livelihood studies.

Let me elucidate the perceived analytical shortcomings that provide my starting point. The first issue concerns the ostensibly unique Torajan obsession with ceremonies and their large contributions to them in material, emotional and social ways. For some, these rituals appear to be so important that they spend most of their entire household budget on them, at the expense of other aspects of wellbeing, such as decent food, healthcare and education. From such a perspective, a livelihood implies much more than the means for dealing with the economic and material objectives in life that are at the centre of most livelihood studies. Livelihood studies aim to be people-centred but usually 'envision man rather narrowly, as a homo economicus mainly occupied with using assets to obtain well-defined economic goals' (Kaag et al. 2004:54). However, much more is at stake in Torajan lives (as in most people's lives) than economic rationality; the aim is as much a matter of meeting what is socially and culturally valued and crucial. Therefore, the social and cultural dimensions of livelihoods are critically important in developing the analysis for this study. As Long (2000:196) argues, in order to understand people's livelihoods one should 'explore the issue of lifestyles and the factors that shape them'. In doing so, it becomes possible to look beyond resources as solely vehicles for making a living and to regard them also as an instrument for making life meaningful and to challenge the structures in which people make a living (Kaag et al. 2004:54).

The second problem faced in framing Torajan livelihoods relates to this issue of 'structures', or what Kaag et al. (2004:54) called the actor-structure 
dilemma in livelihood studies. Livelihood analyses are very much aimed at people's agency, which is hardly surprising when we consider that they were developed as a counterbalance to the poverty alleviation approaches that focused solely on structure. Although human agency, 'the capacity to process experience, make decisions and act upon them' (Long 2000:195), is an important parameter in exploring people's livelihoods, it is certainly not the whole story. A full understanding requires bridging the actorstructure divide by introducing an alternative conceptual focus.

A third issue is that Torajans are agents in a social world. Torajan livelihoods are conditioned by, and part of, social relationships and networks, especially kinship relations. In practice, their livelihood practices can only be clearly understood by taking into account the social networks in which they are embedded, or what I prefer to call the 'social space' that shapes the ways in which people are able to make a living. According to Arce and Hebinck (2002:6), 'People's livelihoods are analytically situated and practised by people in social spaces with boundaries defined by social networks, relationships and identities. These spaces are fluid, constantly changing, and are shaped and constantly renegotiated by people themselves.' As the tongkonan in Tana Toraja seemed to fulfil a key function in anchoring people in a geographical space, a sound perspective on social space, and more specifically on kinship, requires input from studies on house societies.

The final issue concerns translocality or transnationality since a large part of the Torajan population now lives outside the highlands, elsewhere in Indonesia or even beyond. In contemporary social science, the concepts of translocalism and transnationalism have become increasingly popular to explain the connectedness of concrete local practices, and events with the 'wider context'.2 However, in livelihood studies, the use of a translocal lens is still in its infancy. The majority of researchers in this field acknowledge, and some even emphasize, the importance of such a perspective on livelihoods but, as Mazzucato (2004:135) states, 'Most studies...still focus on livelihoods as being created, negotiated and fought for principally in one locality'. A translocal perspective on livelihoods avoids focusing on sedentary communities as the natural state of society and also 'moves beyond simplistic dichotomies of migrants as either moving for economic or political reasons'(Mazzucato 2004:136). Therefore, I would argue that the analysis should focus on the 'dynamics of livelihood' by including a translocal perspective.

2 See for example, Glick-Schiller et al. 1995; Portes et al. 1999; Vertovec 1999; Marcus 1995. 
To come to terms adequately with the issues outlined above, the analysis should not dwell on the actor-structure dilemma, go beyond a single locality, and include time, the cultural dimension and the social space in which livelihoods are created, enhanced and secured. In trying to achieve this, the theoretical section of this book consists of four parts. The first part provides an overview of what is generally understood as a livelihood and how it is conceptualized. ${ }^{3}$ This is essential since, before I come up with new concepts and analytical approaches that better enable me to grasp the full complexity of Torajan livelihoods, I have to make clear my point of departure. In the second and third part, I try to grasp some theoretical handles for the structure-agency dilemma through elaborating on the 'bridging' concept of style. In the following part, the focus shifts to the conceptualization of the 'social space' in which livelihoods are embedded, with an emphasis on kinship and house societies. In the fifth and final part of this section, I will come to terms with the concepts of place and translocality, or transnationalism, that form the basis for a better understanding of translocal livelihoods.

\section{Reconceptualizing Livelihoods}

The livelihoods perspective emerged in the 1980 os and early 1990 s as a reaction to the narrow macroeconomic development approaches that focused mainly on income, employment and the basics needed to alleviate poverty. ${ }^{4}$ These latter approaches were dominating the poverty alleviation programmes (such as the World Bank's Structural Adjustment Programmes) of that time, and positioned the poor as passive victims. Dissatisfied with these structuralist and unitary approaches, social scientists and policymakers united to develop an approach that 'stressed diversity of poverty situations and the multidimensionality of the poverty problem and focused on the agency and the capability of actors, on "strengths" rather than "needs"' (Li 2000 in Kaag et al. 2004:52). Although the concept of livelihoods was not new and had been long used by other social scientists (for example Evans-Pritchard 1940; Kimble 1960; Pandit

3 It is not my intention to provide a complete overview of the genesis and development of the livelihood concept because this has already been done quite extensively by others (most notably Carney 1998; Kaag et al. 2004; De Haan and Zoomers 2005).

4 The most notable contributions to the development of the dominant livelihood approach of that time derived from Chambers (1983), Swift (1989) and Chambers and Conway (1992), Carney 1998. 
1965; Freeman 1975), this period was the first time that a clear framework for analysing livelihoods was developed.

In the following decade, the British Department for International Development (DFID) took a leading role in the further development of a framework for studying livelihoods (De Haan and Zoomers 2005:31). The DFID livelihoods framework appeared to be attractive to researchers and policymakers alike because of its clearly elaborated schemes, diagrams and definitions (Kaag et al. 2004:68). Currently, most livelihood research is inspired by such model-like analytical frameworks. Similarly, DFID made a major contribution to defining the concept of livelihood. The most widely-used definition of a livelihood is still the one developed and reformed by various DFID employees: a livelihood 'comprises the capabilities, assets (including both material and social resources) and activities required for a means of living. A livelihood is sustainable when it can cope with and recover from stresses and shocks and maintain or enhance its capabilities and assets both now and in the future while not undermining the natural resource base' (Carney 1998, based on Chambers and Conway 1992:7). According to Ellis (2000:7), the value of this definition lies in its direct attention to the links between the assets (also including access) and the capabilities that people possess, since these enable or constrain their actions to create, maintain or enhance a livelihood. In this definition, a livelihood is seen as 'a highly complex, all encompassing concept, which is not restricted to the ecological or to the economic or productive aspects of life' (De Haan and Zoomers 2003:356). Notwithstanding the apparent comprehensiveness of the concept, this understanding does not substantially move away from the economic or material objectives of life.

Consequently, several academics ${ }^{5}$ have put more emphasis on the equal importance of other criteria - in particular the cultural and social dimensions that shape people's identity and give them the capability to act (in an accumulative or coping way) on existing and new opportunities and constraints. Bebbington (1999:2022) states that:

A person's assets, such as land, are not merely means with which he or she makes a living: they also give meaning to that person's world. Assets are not simply resources that people use in building livelihoods: they are assets that give them the capability to be and to act. Assets should not be understood only as things that allow survival, adaptation and poverty alleviation: they

5 Most notably, Bebbington 1999; Long 2000; De Haan and Zoomers 2005; Mazzucato 2004; Kaag et al. 2004. 
are also the basis of agents' power to act and to reproduce, challenge or change the rules that govern the control, use and transformation of resources.

Long (2000:197) also stresses the importance of including the social and cultural dimensions in livelihood studies; and uses Wallman's contribution (1984) for pointing to the fact that a livelihood is much more than 'finding or making shelter, transacting money, getting food to put on the family table or to exchange on the market place'. According to Long (2000:197), a livelihood encompasses:

value choice, status issues, identification with or distantiation from other modes of living and types of social persons. It implies both a synchronic pattern of relationships existing among a delimited number of persons for solving livelihood problems or sustaining certain types of livelihoods, as well as diachronic processes. The later cover actors' livelihood trajectories during their life course, the types of choices they identify and take, and the switches they make between livelihood options. Livelihoods are both individually and jointly constructed and represent patterns of shifting inter-dependencies.

In this respect, Long (2001:241) also states that livelihoods 'are made up of practices by which individuals and groups strive to make a living, meet their consumption necessities, cope with adversities and uncertainties, engage with new opportunities, protect existing or pursue new lifestyles and cultural identifications, and fulfil their social obligations.'

Echoing Bebbington and Long, other authors continue to stress that livelihoods should be considered as a dynamic and holistic concept (for example, Ellis 2000; De Haan 2000). However, often these authors do not really move beyond material motives and aims, and continue to focus on capital and activities, and downplay structural features (De Haan and Zoomers 2005: 33). They still use model-based approaches to livelihoods, giving the impression that analytical distinctions are real-life distinctions that can be put into specific boxes (Hospes and Lont 2004:8-10). They also remain focused on 'livelihoods as being created, negotiated and fought for principally in one locality' (Mazzucato 2004:135). In the following sections, I will attempt to add greater theoretical depth to the livelihoods discussion by elaborating on the ideas of livelihood style, social space and place, geographical place and translocality.

\section{Livelihood Styles: Beyond Agency and Social Structure}

Contemporary livelihood studies have not, therefore, changed much in focus over the past two decades and are in principle still centred on the 
'active role' that people play in responding to and bringing about change. Through emphasizing people's situated agency, that is, the way in which people 'actively shape their lives in particular contexts through material and non-material assets', analysts have tried to change the image of poor people as mere victims of structural constraints In the light of this desire, it is rather understandable that livelihood practices are often treated as if they are purely individual strategies and thus result of people trying to achieve predefined goals through rationally planned actions (Kaag et al. 2004:53 and 67).

Rather than denying the importance of people's agency in achieving a livelihood, I argue that there is much more involved than the deliberate motives or more conscious strategies of individuals or of groups. The anecdotes in the introductory chapter show that the practices of most Torajans seem intrinsically bounded and determined by the social structures in which they are embedded, even if they are no longer living in Tana Toraja. A view that looks solely on Torajan actions and strategies runs the risk of downplaying the social structures that shape them if not necessarily determining them. Archer (1988:ix, 1995) calls the basic issue in contemporary social theory 'the problem of structure and agency', namely the constant tension between the two influences. According to Miles (2000:19) 'This point [the interface between agency and structure] is acutely evident at an everyday experiential level, where we see that life is actively constituted by the contrary feeling that the individual is both free and yet somehow simultaneously constrained.'

I do not intend to provide a complete account of this dichotomy ${ }^{6}$ but rather to bridge the debates on structure and agency by more realistically putting forward an alternative conceptual focus-on 'styles', or more specifically, on 'livelihood styles'. The value of the sociological concept of (life)styles for the analysis of livelihoods 'lies in the way in which it addresses the duality of structure and agency' (Miles 2000:18-9). By employing the concept of style it becomes possible to treat people as agents in the social world. Moreover, styles help to explain what people do, why they do it, and what doing it means to them and others (Chaney 1996:4). In this way, the concept of styles seems also to promise to avoid the rigid 'sectoral approach to livelihood strategies as if resources and resource systems are actually separated from each other and consequently each can be put in a special box' (Hospes and Lont 2004:10). Finally, the

${ }^{6}$ See for more detailed elaborations, for example, Sztompka 1993; Ritzer and Goodman 2004 . 
concept of styles helps to analyse people's patterns of livelihood practices, not only as the outcome of strategically planned actions for making a living, but also as the (unconscious as much as conscious) actions to protect existing lifestyles or to pursue new lifestyles and cultural identifications, and to fulfil their social obligations. Besides, it includes practices that are meant to consolidate existing power or to strive for greater political power. As the livelihoods approach has a somewhat non-ideological standpoint, this dimension is rarely touched upon in contemporary livelihood studies. ${ }^{7}$

The concept of style is not completely new within the analysis of livelihoods. Arce and Hebinck (2002) introduced the concept in an unpublished paper as a means to analyze the impact of socio-cultural components within the livelihood framework. They use the notions of lifestyles or 'styles of farming' almost interchangeably as an argument against the concept of livelihood strategies, and build their argument along the lines of the 'styles of farming approach' developed earlier at Wageningen University. ${ }^{8}$ By suggesting that style involves a more sophisticated analysis of livelihoods because it goes beyond the level of individual strategies and incorporates the significance of organized practices they contend that a 'style of farming' comprises four interrelated and mutually dependent levels of social analysis: (1) a specific cultural repertoire composed of shared experiences, knowledge, insights, interests, prospects and interpretations of the context; (2) an integrated set of practices and artefacts, such as crop varieties, instruments, cattle and cropping schemes; (3) a specific ordering of the interrelationships between the farming unit and markets, technology and institutions; (4) the way in which local people respond to agrarian policies (Arce and Hebinck 2002:8-9). Arce and Hebinck argue that the analysis of styles of farming has proved to be useful because of 'its clear set of analytical instruments and the way the concept disentangles diversity and differentiation' and therefore it should encompass other lifestyles and move beyond farming.

In a field somewhat related to that of livelihood studies, that of social security, Nooteboom (2003) also applied the concept of style in the analysis of communal institutions that provide social security on the one hand,

7 The study of De Haan and Zoomers (2005) is a notable exception; it discusses power relations in the livelihoods approach in order to fully conceptualize access.

8 For example, by Bolhuis and Van der Ploeg 1985; Hebinck and Van der Ploeg 1997; Van der Ploeg 1999. 
and the space for individuals to make use of this security on the other. ${ }^{9}$ As with Arce and Hebinck, Nooteboom took the idea of styles loosely from the styles of farming approach developed at Wageningen. On the basis of these studies, Nooteboom (2003:54-5) defines styles (of social security) as 'distinguishable patterns of orientations and actions concerning the variety of means to achieve security; these patterns are structured by an internal logic and conditioned by social, economic, and personal characteristics of the people involved'. Both of these studies consider styles as emic social constructions. In this respect, Nooteboom argues that 'people do not follow a style, but have a style of organizing their social security' and that therefore this differs from strategies designed by individuals.

Although both studies provide some interesting insights into the notion of style, and emphasize its relevance for the integration of socio-cultural components as well as it being a way to move beyond the structure-agency divide, they have left many dimensions of the concept underexposed and without a satisfactory elaboration. In addition to styles, De Haan and Zoomers (2005:41-3) applied the concept of pathways, defined as 'patterns of livelihood activities which arise from a co-ordination process among actors. This co-ordination emerges from individual strategic behaviour embedded both in a historical repertoire and in social differentiation, including power relations and institutional processes, both of which play a role in subsequent decision-making'. The term 'pathways' has become more popular in contemporary livelihood studies ${ }^{10}$ and De Haan and Zoomers have been using these studies to build up a definition. Their argumentation and definition provide interesting new insights into the theoretical discussion on livelihoods. For the analysis of the full complexity of Torajan livelihoods, the concept of pathways is particularly useful in stressing the dynamics of livelihoods or, more specifically, the pattern of livelihood practices that 'is generative and develops and changes over time because of the logic of practice' (De Haan and Zoomers 2005:41).

We need to explore the concept of style further to define more precisely what is meant by the term, and to identify its value for livelihood studies as an analytical tool. I will do this on the basis of a deeper analysis of Giddens and Bourdieu's 'distinctive notion on styles' which has been

9 Though Nooteboom (2003) does not employ the concept of lifestyle, his discussion of styles is actually based on earlier writings on lifestyles and farming styles, and therefore when he uses the word 'styles', one could also read it as 'lifestyles'.

10 See, for example, Breusers 2001; Pender et al. 2001; Scoones and Wolmer 2002; De Haan and Zoomers 2005. 
instructive in the sociological discussions of styles, or more specifically of lifestyles. De Haan and Zoomers (2005:41) note that the attention to styles in livelihood studies 'can be seen as an attempt to move away from neoliberal thinking to a more structural approach - from Giddens toward Bourdieu's 'habitus'. I want to make clear once again that I see the value of the concept of styles precisely as a way of bridging the agency-structure divide and, as such, it does include elements of both Giddens and Bourdieu, rather than either one or the other. Both have provided useful tools to sociology and, more specifically, their conception of lifestyles which helps in obtaining a more thorough understanding of the relationship between structure and agency (Miles 2000:23). Here I think it is useful to outline some of the fundamental notions of Giddens and of Bourdieu on the study of the agency-structure divide and lifestyles before proceeding to a discussion on its usefulness for livelihoods analysis.

Anthony Giddens' structuration theory (1984) is probably one of the best-known and most accomplished attempts to integrate structure and agency (see Ritzer and Goodman 2004:509). This theory emphasizes the 'duality of structure', meaning that action and structure cannot be conceived separately as they are in fact two sides of the same coin. On the one side, social structures are created by human agency and, on the other, social structures are the very medium of this constitution (Giddens 1976:121). In this context, Giddens (1984:2) argues that it is 'neither the experience of the individual actor, nor the existence of any form of social totality, but social practices ordered across time and space' that should be taken as the basic domain in the study of the social sciences. Agency and structure are thus inextricably interwoven in ongoing human activity or practice (Ritzer and Goodman 2004:510). Social practices, as the proper units of analysis, are not considered to be discrete actions but rather ongoing streams of actions. This continuity of social practices presumes reflexivity or consciousness, implying that human actors are not merely self-conscious but are also engaged in the monitoring of the ongoing flow of social life (Giddens 1984:3). As such, 'activities are not produced by consciousness, by the social construction of reality, nor are they produced by social structure. Rather, in expressing themselves as actors, people are engaging in practice, and it is through that practice that both consciousness and structure are produced' (Ritzer and Goodman 2004:510).

Giddens thus regards human actors (or agents) as the ultimate motor of structuration (Sztompka 1993). In so doing, he accords actors great power, in a sense that they have 'the ability to make a difference in the social world', while at the same time emphasizing that they cannot act in any 
meaningful way without drawing upon collective interpretive schemes that enable and constrain their actions (Ritzer and Goodman 2004:511; Calhoun et al. 2002:223). Structure is thus not viewed as a barrier to action, but rather as essentially involved in its production (Giddens 1984:17). As such, Giddens (1984:179) notes that 'there is no such thing as a distinctive type of "structural explanation" in the social sciences; all explanations will involve at least implicit reference both to the purposive, reasoning behaviour of agents and to its intersection with constraining and enabling features of the social and material contexts of that behaviour'.

Against this background, Giddens developed a perception of lifestyles that encompasses most of the central issues touched upon in his theory of structuration. According to Giddens (1991:81-2), a lifestyle involves 'a cluster of habits and orientations, and hence has a certain unity...that connects options in a more or less ordered pattern....[T]he selection or creation of lifestyles is influenced by group pressures and the visibility of role models, as well as by socioeconomic circumstances'. He defines lifestyles as:

a more or less integrated set of practices which an individual embraces, not only because such practices fulfil utilitarian needs, but because they give material form to a particular narrative of self-identity. ...Lifestyles are [thus] routined practices, the routines incorporated into habits of dress, eating, modes of acting and favoured milieux for encountering others; but the routines followed are reflexively open to change in the light of the mobile nature of self-identity.

In this explanation of lifestyles, Giddens puts the streams, or integrated set of routinized practices of agents, at the centre of lifestyles; while taking into account the influence of social structures in which they are embedded, and acknowledging the reflexivity of agents that enables change in the routines of everyday practices.

While including both structure and agency in his notion of lifestyle, Giddens tends to put the emphasis on the latter and fails to really grasp the social structures that underlie the social world (Craib 1992). Bourdieu, on the other hand, favours a position that is more structuralist, though not losing sight of the agent. Like Giddens, Bourdieu sought to bridge the extremities of structural and interactionist approaches to social life. Although he succeeded to some degree, there is a bias in his work towards structuralism (Ritzer and Goodman 2004:520). Bourdieu (1977, 1990) advanced a 'relational analysis of social tastes and practices' as a means of obtaining an empirical handle on the dynamic relationship between structure and action; or, in his words, by escaping from both subjectivism 
and objectivism. His analysis involves the three concepts of 'position', 'dispositions' (or habitus) and 'position-taking' (practices) which have appeared pivotal in most of his work. According to Bourdieu, the complete set of positions make up social space. Each position is occupied by an actor on the basis of their occupation, education or proximity to power. Positions are maintained and expressed to others through a process of position-taking whereby they produce social status for their occupants (Calhoun et al. 2002:260-1). People express their position through a particular style of clothing, leisure activities, consumer patterns and so on. However, there is no hard connection between positions in the social space and the practices related to them; they differ in times and in spaces. Rather than having a permanent connection, structure and practice are linked together by the habitus. By 'habitus' Bourdieu (1989:19) means:

A system of schemes of perception and appreciation of practices, cognitive and evaluative structures which are acquired through the lasting experience of a social position. Habitus is both a system of schemes of production of practices and a system of perception and appreciation of practices. And, in both of these dimensions, its operation expresses the social position in which it was elaborated. Consequently, habitus produces practices and representations which are available for classification, which are objectively differentiated; however, they are immediately perceived as such only by those agents who possess the code, the classificatory schemes necessary to understand their social meaning.

As the habitus (or dispositions) of agents are 'the mental structures through which they apprehend the social world [which] are essentially the product of the internalization of the structures of the world' (Bourdieu 1989:18), they cannot be studied directly since they are only observable through practices. In this respect, habitus both implies a 'sense of one's place' as well as a 'sense of the place of others' or, in other words, provides us with a world with a common sense: a world that seems self-evident. 'It is on the basis of habitus that Bourdieu defines social groups (including social classes), since those who occupy similar positions in the social structure will have the same habitus '(Calhoun et al. 2002:261).

In his work on Distinction, Bourdieu (1984) argues that the habitus of a person, or a group of persons that occupy a similar or neighbouring position in social space, is in a way quite systematic. All the elements of a person's behaviour have something in common, 'a kind of affinity of style' (Bourdieu 2002:28). Bourdieu uses the example of handwriting to underpin his argument. Whether a particular person 'writes with instruments as diverse as a pencil, a pen or piece of chalk and on media as different as a 
sheet of paper and a blackboard', his or her style of handwriting will be immediately recognizable. He calls this a 'practical systematicity' to denote that it is not necessarily logical. Bourdieu continues his argument, and accepts that there are variances and exceptions but sees the word 'style' as indicative of this practical unity. He acknowledges that an emphasis on this unity is in danger of being regarded as supporting the idea that human behaviour is monolithic - which is sometimes put forward against the notion of habitus - but makes clear that human behaviour is not monolithic. Rather, 'It is very open, very diverse, but within limits, and the idea of lifestyle is suited to express this loose systematicity which characterizes human behaviour'. In line with the above argumentation, Bourdieu (1984:172) defines lifestyles as 'the systematic products of habitus, which perceived in their mutual relations through the schemes of the habitus, become sign systems that are socially qualified (as 'distinguished', 'vulgar, etc.)'.

Bourdieu's contribution to the understanding of lifestyles has proved useful in explaining why contemporary socio-structural distinctions are increasingly articulated through cultural forms (Chaney 1996:65). Lifestyles are about behaving in culturally acceptable ways and depend upon someone's cultural capital. The more cultural capital someone possesses, the more extravagant that person's lifestyle is likely to be (Miles 2000:23). In that sense, certain activities are considered more culturally appropriate than others, and these are hierarchically ordered. As such, lifestyles fulfil an active role in maintaining social hierarchies because some people have more access to cultural (and economic) capital than others. Accepting this argument, and from Bourdieu's point of view, group contexts and influences are of great importance in the construction of people's lifestyles.

Although Bourdieu has provided an interesting theoretical framework for the analysis of lifestyles that is based on some fascinating empirical work, it is not surprising that his work has been criticized as being overly deterministic (see, for example, Chaney 1996). To put it differently, there seems to be no conceptual (or empirical) space for the human agent in Bourdieu's framework, and the use of the term 'reflexitivity' is questionable. As Chaney (1996:66) observes, 'The very prescriptive determinism of his concept of habitus does not allow him to fully appreciate the ways in which actors may and will play with these [lifestyle] choices as ironic commentaries on their own styles of life'. Chaney continues his argument by adopting a quote by Rigby (1991:123 quoted in Chaney 1996:66): 'Bourdieu's view of the role of culture in modern society is not only very pessimistic 
but also rather outdated'. With this summation he reflects the processes of modernization and globalization (such as increasing suburbanization, migration, the increasing dominance of retailing in anonymous shopping centres) that seem to have diminished rather than enhanced cultural diversity. According to Chaney (1996:145), these processes have also become 'an inextricable part of the same social and economic changes that have been the context of lifestyle identifications'.

\section{Livelihood Style Defined}

In spite of the criticism of both Giddens's and Bourdieu's studies of contemporary lifestyles, I believe that taken together they cover most issues of styles and the factors that shape them and, therefore, provide the fundamentals for coming to grips with the term and discussing its usefulness in the study of livelihoods. Apart from their differences over emphasising either the role of agency or that of structure, they do deliver several analogous aspects in their endeavours to analytically frame the concept of style. They both depart from human practices as the central focus of analysis. As such, they stress the routine nature or systematicity of these practices that are more or less ordered in a pattern and hence show a certain unity. Both authors admit that this pattern follows from the social context (or social space), social differentiation and socioeconomic circumstances (or place) in which it is embedded. Further, they both take the historical, or time dimension, into account, and regard these patterns of practices as a product of time. This reflects the ideas of De Haan and Zoomers (2005:41), who argue that although the results may be the same, the pathways might have been different. In this respect, Giddens and Bourdieu consider styles to be important in expressing one's own, or someone else's, position in society or, in other words, as a means to obtain an identity or social status. However, the main difference lies in the plasticity of styles and the actors' potential to actively bring about change in their style of living.

In Bourdieu's perspective, styles are more or less defined by people's position in the social space. Their various positions and thereby styles are the result of the actors' historical trajectories in arriving at the positions that they now occupy. These trajectories, in turn, correspond largely to a given volume of inherited capital. '[T] he shift from one trajectory to another often depends on collective events-wars, crisis, etc.- or individual events - encounters, affairs, benefactors etc. - which are usually described as fortunate or unfortunate accidents' (Bourdieu 1984:110). 
In this sense, Bourdieu largely ignores reflexitivity, the capacity or capability to reflect on one's practices, and change them if desired-which is so important in Giddens' account. Even if the room for manoeuvre is very limited because of the social structure in which an agent is embedded, styles are never completely static according to Giddens. Or, seen from another perspective, in Bourdieu's explanation there is hardly any room for deviant behaviour or styles, whereas in Giddens' reasoning there is. Along the same lines, Bourdieu ascribes a much greater role to culture in defining or determining people's styles than does Giddens.

As I argued above, a satisfactory definition of style for the analysis of livelihoods, or as I prefer to call it 'livelihood style', cannot be based on either Giddens's or Bourdieu's accounts of lifestyle, but must include aspects of both explanations. Accordingly, on the basis of a synthesis-like approach, I define livelihood style as

A recognizable and coherent pattern of practices that results from an actor's conscious and unconscious objectives in establishing, maintaining, and enhancing a living in interaction (both in a cooperative and conflicting manner) with other actors over time, and within the framework of status systems, cultural ideals and geographical space and place(s).

In this sense, livelihood styles can be perceived as a fairly stable unity of practices that are objectively differentiated; however, the perception of styles by the agents embodied in them (emic view) does not necessarily coincide with the perceptions of the same styles by the ones observing them (etic view). This idea contrasts with the view of Arce and Hebinck and of Nooteboom who consider styles to be specifically an emic notion.

The term 'style' does not imply that daily lives are homogeneous. Rather, the key issue is that people have a great variety of options (in resources, social relations, cultural repertoires, and so on) in a given context to establish a livelihood. Despite these options, particular livelihood styles, or clusters of livelihood styles, emerge as the outcome of the whole gamut of practices that are reflected in the impressive heterogeneity of daily lives (Long and van der Ploeg 1994:70). Although particular livelihood styles might emerge over time, these styles are dynamic and susceptible to change. Changes in styles are both embedded in the style itself, even if this is not observable at first glance, as well as triggered by the context in which styles are embedded. The first aspect of change concerns actors' livelihood trajectories during their life courses, the types of choices they identify and make, and the switches they make between livelihood options (Long 2001:55). The latter form of change is often seen as more important than 
the first, especially when it comes to abrupt changes due to particular disasters or crises, but we should be careful not to exaggerate the importance of the contextual factors to which the agent is exposed. As Long and Van der Ploeg argue (1994:77), such factors are not relevant as 'determinants' when self-evident limits exist beyond which action is judged to be inconceivable. 'Rather, [they are relevant] as boundary markers that become targets for negotiation, reconsideration, sabotage and/or change, i.e. as barriers that have to be removed or transformed" (Long 2001:63). Given this 'double way of change', which is inherent to livelihood styles, these styles in fact represent an analysis of the 'work in progress' or, in Bourdieu's words (2002), the modus operandi.

Moreover, I argue that livelihood practices are embedded in social differentiation. Or, in other words, in social space, and in the struggles and negotiations that take place within it, since people generally but not necessarily act according to their position within it. Patterns in livelihood practices exist because various people face similar inherited attributes (such as age, gender, ethnicity and descent) and achieved attributes (such as educational credentials and political position) that provide them with similar opportunities and expectations. In Bourdieu's terms, patterns in livelihood practices arise because people from the same social class, gender or caste have similar dispositions ${ }^{11}$ and therefore face similar life opportunities and expectations of others (De Haan and Zoomers 2005:41). Agents have some room to manoeuvre within these (dis)positions in order to obtain a living, and are able to change their social positions. Although social structures might not determine people's livelihood styles as rigidly as Bourdieu argues, in any society some ordering principles or boundary markers at least guide people in their perceptions of the social space and their position within it, thereby shaping their life opportunities and their expectations of others in establishing, maintaining or enhancing their wellbeing. As these principles are generally locally bounded, livelihood styles can only be explained with reference to the local context in which they are embedded.

In this perspective, the term livelihood style enables me to analyse the full complexity of Torajan livelihoods by focusing on the patterns of practices that individuals and households employ to compose, maintain

11 A disposition is a habit, a preparation, a state of readiness, or a tendency to act in a specified way. In Bourdieu's theory of fields dispositions are the natural tendencies of each individual to take on a certain position in any field. There is no strict determinism through one's dispositions, though in retrospect, a space of possible practices can always be observed. 
and enhance wellbeing, without predetermining whether these practices are the result of conscious or unconscious choices. In so doing, it becomes possible to identify the most prominent life objectives (material and nonmaterial) in Tana Toraja, which in turn lead to or correspond to a particular livelihood style that by definition is not designed simply to make a living. If at the same time we take into account the influences of the social space, social differentiation, cultural ideals, place and time in which the actors are embedded, we can see to what extent these goals and the design of a livelihood style are bounded (as markers) by these factors. Moreover, it enables us to consider whether Torajan livelihood styles are locationspecific (in both a social and geographical sense) and even, more importantly, whether particular styles are more vulnerable or resilient to changes in context than others. This differs from earlier approaches to livelihoods in that livelihood styles do not explain the vulnerability of people's lives solely by looking at assets, capabilities or the activities of agents, but also encompass people's perspectives or objectives in obtaining a living, and also the more cultural aspects and contexts that shape these aspects. In short, the concept of livelihood styles provides a framework for explaining the way people make a living in Tana Toraja as something which is more than the outcome of economically valuable resources being strategically mobilized for making a living. As such, the concept of livelihood styles seems promising as a way out of the paradox posed in the introduction of this book: how is it possible that while the economic activities in Tana Toraja declined, and the costs for daily life increased, that the exorbitant Torajan expenditures on funeral ceremonies continued or even increased?

\section{Livelihoods and Social Space: Networks, Kinship and Houses}

Styles point toward the idea that we should not think of a collection of rational actors but rather of people who have a number of scenarios at their disposal, shaped by context and structural aspects. Further, agency means that people opt for a particular style within this structural room for manoeuvre. Styles could be considered as a kind of patterned behaviour in which the emphasis is on the cultural aspects that shape them. Moreover, styles emphasize that people are not opting for particular practices in a social vacuum but, rather, that they are part of particular groups, or more specifically, networks of social relations. Through social relations, people's styles are positioned in the social world. For example, in the organization of a drama, there are a variety of scenarios possible from which the actors 
can choose. However, at the same time, their choice of a particular play or role depends on the people they have at their disposal. Moreover, from the outside, the drama might appear to be a well-orchestrated performance whereas, behind the scenes, people might be competing to get the most popular role. To understand why people choose particular scenarios or styles, and how they come about, it is thus necessary to take account of the social dimension or social space. I am not suggesting that people are completely bounded by social space, but that the risk of being expelled or excluded from particular social relations means that people usually refrain from freeriding.

Thus the practices that make a living are created, maintained, enhanced and adapted in interactions - in both cooperative and conflicting manners-with other actors. This means that people's livelihood styles are, in analytical terms, situated in social spaces with boundaries defined by social networks, relationships and identities. 'These spaces are fluid, constantly changing, and are shaped and constantly re-negotiated by people themselves' (Arce and Hebinck 2002:6-7). Livelihood styles can only be properly understood by mapping the various actors and the networks and social relationships among them. As Granovetter (1992:25) argues, all action (in the sense of economic action) 'is socially situated and cannot be explained by reference to individual motives alone. It is embedded in ongoing networks of personal relationships rather than carried out by atomized actors.' The question then is, what does this space looks like, and in what sense is it constraining or enabling people's behaviour? This boils down to the idea of positive and negative social capital—-terms that have become popular in conceptualising the social dimension. In the following sections, I will elaborate on the various aspects that make up the social space in general, and try to obtain some analytical handles for mapping the Torajan social space in particular.

Torajan livelihoods are imbued with social relationships and networks, especially kinship relations. 'Practical' kinship relations, in Bourdieu's words (1977:37), are highly instrumental in Torajans' success at achieving wellbeing. Although kinship may not be the only element in the social space of Torajan society, it certainly appears to be one of the most important factors among the many that make up the basis of the structure of Torajan relationships and networks. As Bourdieu argued (1976:141 in: Schweizer and White 1998:1), kinship and marriage grow out of '...practical and complex strategies. They are part of an entire system of biological, cultural, and social reproduction', and in this sense they are fundamental to the constitution of social relations. In the following 
sections, I postulate some theoretical ideas on kinship in general, and more specifically on insular Southeast Asian notions of kinship. As the tongkonan in Tana Toraja seems to fulfil a key function in anchoring people in space and linking them in time, I add some perspectives on kinship from the studies on so-called 'house societies'.

\section{Social Relationships and Networks}

A fruitful analysis of any human action...requires us to avoid the atomization implicit in the theoretical extremes of under- and over-socialized views. Actors do not behave or decide as atoms outside a social context, nor do they adhere to a script written for them by the particular intersection of sociocultural categories they happen to occupy. Their attempts at purposive action are instead embedded in concrete, ongoing systems of social relations (Granovetter 1992:31).

I quote Granovetter to emphasize that my purpose is to find a balance between an oversocialized (deterministic, cultural) view of practices, and an under-socialized (individualist, atomized) perspective by focusing on the way in which social relations and networks of relations shape the livelihood practices of human agents for better or for worse. Thus, the stress on social relations goes beyond the particularized individual and also deals with the ambiguous complexities of friction, where relationships exhibit both cooperation and conflict (Schuller and Field 2000). In so doing, I do not aim to account completely for all social network studiesand no-one is quite sure whether a network is a metaphor, a method or a theory (Barnes 1979). Rather, I will establish a conceptual analysis that stems from various social network studies (and to some extent from social capital studies) ${ }^{12}$ that will help me to further analyze Torajan social life as an essential element of the available livelihood styles.

Social networks are seen as the set of relations or ties among actors (for example, Mitchell 1973; Wasserman and Faust 1994; Schuller and Field 200o). Actors are regarded here as discrete individual, corporate or collective social units, such as individuals, households, organizations and social groups (Wasserman and Faust 1994). Actors are linked to other actors by social ties. A collection of ties of a specific kind involving a specified set of actors is referred to as social relations. Social relations can be as diverse as kinship, friendship, village or neighbourhood membership, patron-client,

12 And to some extent to social capital studies that often adopted key terms from social network studies and then refined them and developed them further. 
political party membership and so on. Social relationships can be mapped as a grid of ties that involve both content and form. Mitchell (1973:23-6) extracts three different types of content from the social network literature of that time, which still largely resembles contemporary accounts: communication content; normative content; and exchange or transformation content. The first of these relates to the passage of information between actors. The second concerns the expectations that actors have of other actors because of some social characteristic or social attribute the other may possess. Mitchell (1973: 27) relates these expectations to a 'common sense of meaning' that actors attribute to the relationship. Wasserman and Faust (1994:38) would label these two content types as transfers of non-material resources. The third content can be conceptualized as the links between actors in social networks created by the set of transactions or transfers of material resources. This includes social support such as lending and borrowing items, business transactions (sales or purchases of goods) and the exchange of gifts. To summarize, the relational ties between actors can be seen as channels for the transfer or flow of non-material as well as material resources (Schuller and Field 2000).

Besides content, a tie can also be articulated in form, which concerns the strength of a relation. Relations range from weak to strong. Weak ties can be characterized as links between actors that have infrequent contact and who do not attach great significance to the relationship (Schensul et al. 1999:13). At the other end of the continuum, strong ties imply a great intensity of interaction between actors in relationships that are highly valued. Examples of strong ties that are often given are relations between family or kin, friends and close colleagues. In livelihood studies, strong ties are usually regarded as the most important in maintaining a living because one trusts family and friends, and they are the first ones to call upon (De Haan and Quarles van Ufford 2002:289). Nevertheless, in his seminal work, Granovetter (1973) has shown that, on some occasions, weak ties might also appear to be quite strong. They can function as bridges to other networks that contain information or contacts not available within one's own network. Following Granovetter, several authors - mostly in the field of social capital-have elaborated on bridging and cross-cutting ties as a way to open up different networks and thereby additional resources (see for example Narayan 1999; Putnam 2000; Woolcock 1998).

Knoke and Burt (1983) emphasize that ties between two actors can be either symmetric or asymmetric in the amount and type of resources that flow between them. However, in reality most ties are asymmetric in content and strength because a strict one-to-one correspondence between 
what two persons give to one another is rare (Wellman 1988:40-1). Wellman states, 'Although rarely symmetric, ties are usually reciprocated in a generalized way. For example, not only do clients send resources to patrons, but patrons usually send such resources as goods, information, and protection to clients. Further, the power of patrons is partly based on their ties with clients, as the ties themselves are a scarce resource".

Thus, to make a living, people may employ a variety of social relationships that vary in content, strength and direction. These social relationships are rarely differentiated from 'ordinary' social and economic relationships that serve normal life situations (Von Benda Beckmann et al. 1997:109). According to Von Benda-Beckmann et al., the livelihood dimension of these relationships is often just one of many facets 'that are interwoven in complex social relationships' In this respect, relationships can be regarded as multifunctional-as devices for livelihood provisions but also with potentially economic, political and social functions. It should be emphasized that dyadic social relations are generally part of larger social networks and can therefore not be well understood in isolation from the social context in which they are embedded (Granovetter 1992). In Howard Aldrich's words (1982:286), '...transactions within networks are influenced by properties of the field of relations surrounding them'. As such, patronclient relations, for example, should be treated as local manifestations of larger class structures (Bodemann 1988). To push this argument a little further, people are not only embedded in multifunctional relations but also in the multiplex networks of which these relations are part. Multiplexity here refers to overlapping social networks in which the same people are linked together across different speres or dimensions of life (Portes 1998). Boissevain (1974) gives the example of a small town in which the same individuals may simultaneously be kin, neighbours and co-workers and hence be linked to the same network of people through multifunctional relations.

Now, the thorny issue of the boundaries of these networks arises: what are the boundaries of these networks and how are they defined? ${ }^{13}$ The most common strategies for boundary specification are based on a distinction between emic approaches that take the subjective perceptions of actors as a starting point and the etic approaches that depart from the observer's point of view (Mitchell 1973; Lauman et al. 1983 quoted in Marsden 1990). In both views several criteria can be chosen to define the

13 This parallels the general problem in social science of defining the population to which research results can be generalized (Marsden 1990). 
boundaries of networks: (1) actors' attributes that define inclusion or membership criteria for more formal organizations such as schools, church choirs, political parties, but also for less formal domains such as kinship or peergroups. Individual attributes are, for example, age, gender, socioeconomic status, and place of residence, and the like; (2) participation in events, such as funeral ceremonies or gambling parties. 'Events usually occur at discrete points in time, as well as in geographical places' and usually concern attributes of both the actors and of the event (Wasserman and Faust 1994); (3) networks focusing on a particular problem, a resource, an idea or a social condition. Thus, the existence of common aims and interests among a set of people (Mitchell 1973); and finally (4) the relational character of networks, such as the content of ties (particular exchanges for social security for example). It does not need much explication to see that boundary specification becomes more difficult in large-scale and complex societies, where individuals interact with a great number of people on different bases, on different occasions and in different places. Moreover, it is apparent that these boundaries are not static and change. Even the composition of close kinship groups changes over the lifetime of its members. Seen in this way, partial networks or (corporate) groups so bounded are always an abstract construction of either the participants, or the sociologist who is observing them, or both (Mitchell 1973:32). Nevertheless, when it is made clear from the outset whether the networks described are from an 'emic' or an 'etic' perspective, and which principles are used in drawing boundaries, a network analysis provides useful insight into the way in which social space(s) shape people's livelihood practices.

Yet, if we are to accept the finiteness or boundedness of networks of social relations - at least in abstract terms - we need to consider the concept of 'social position' which is in a sense an abstraction from bounded networks or groups. Position can be defined as 'the location of an actor or class of actors in a system of social relationships' (Gross et al. 1958 quoted in Mitchell 1973:30). Whether desirable resources, and information on accessing them, are made available through network connections depends largely on one's position in the network (Smith-Doerr and Powell 2005:391). In this regard, position in a network both empowers and constrains the actions of their incumbents. Through certain network positions actors have greater access to, and potential control over, relevant resources (Krackhardt and Brass 1994:210). Being in these more fortunate positions, actors increase others' dependency upon them and wield more power. Good illustrations of such positions are gatekeepers and brokers. 
Gatekeepers, for example, might control access to an organization's leader from which they may gain wealth, flattery, influence, the use of organizational resources and so on. Brokers hold a central position by linking two kinds of network clusters and, as such, might take a share of the resources that pass through their position (Wellman 1988:45-6). In addition to brokers and gatekeepers, we might also think of central positions in political networks, neighbourhood or community networks, kinship networks, and the like. Although people in central positions might increase others' dependence upon them, they also have to increase their dependence on others in order to have access to relevant resources that are not controlled or mediated by those others (Krackhardt and Brass 1994:210).

Long (2001:56) stresses the importance of including a focus on those social networks that are composed of uneven and partial sets of relations, and that strain toward patterns of centralization and hierarchy. He argues that most authors 'depict networks as made up of relatively balanced and dense sets of relations based on principles of reciprocity' but that this is often not the case. Social network studies often fail to address issues of conflict and power and overlook the possibility that networks might also have a dark side. Intense trust and bitter rivalry usually coexist in most densely-knit networks. Competition over access to scarce resources is inherent in social space and leads to collaboration and more-or-less bounded coalitions and factions (Wellman 1988:46). Network analysts in particular, trying to explain the structural basis for political activity, have demonstrated how acts of collective violence (for example food riots or rebellions) are integral parts of broad conflicts over power fought by various interest groups. Interestingly, those engaged in collective violence are not the uprooted, disconnected individuals but rather those more deeply rooted and more densely knit into competing groups. In general, such people appeared to be the most likely to be politically active, whether this activity occurred in violent or non-violent ways.

Although power is usually thought of as a resource that individuals, or clusters of social relations, can possess, accumulate and unproblematically exercise, a more fruitful way of thinking about power flows from feminist or gender studies. These studies (see for example Kabeer 1994) point to the fact that power is much more than how hierarchies and hegemonic control demarcate social positions and opportunities, and restrict access to resources. They do not focus on 'power-over' but stress a 'powerto' view - the capacity to do things, to achieve goals, no matter how small the room for manoeuvre is within particular situations. Villareal (1994) shows in a lively account of women's empowerment that power never 
fully belongs to either of the two people involved in a particular interaction. Power is the outcome of complex struggles and negotiations over authority, status, reputation and resources, and it necessitates the acquisition of networks of actors and followers (Long 2001:71). Seeing power in this way, Villareal argues that 'power relations are re-created in interaction and thus constitute a dynamic process of "wielding and yielding". The wants of the power wielder are influenced and shaped by the other in the subordinate position. From this point of view, women are not pure victims, but also have an active role in their subordination' (Villareal 1994 in De Haan and Zoomers 2005:37). If we relate this view to a person's position in a network, it becomes clear that, through the wielding and yielding process, people are continually creating room to improve or protect their position within social space.

Having said this, there is still one issue I need to raise with regard to the analysis of social relations and networks, namely, the ordering principles that are embodied in them. Ordering principles 'should not be seen as fixed institutional frames or normative criteria, but rather as flexible or contestable interpretive modes that give some order to the flux of social life' (Long 2001:56). The scope of these ordering principles varies greatly between societies and criss-crosses different domains of life. Given this situation, I will not continue with an exposition on general or universal ordering principles but instead focus on the specific ordering principles that prevail in South Sulawesi. This will be discussed below but, before getting there, I will first try to get a better analytical grip on the most common social relations and networks in Torajan society—those defined by kinship and houses.

\section{Networks of Kin}

The reason for discussing kinship here is well reflected in the words of Kemp and Hüsken (1991:7), '[it] arises not from some specific project to study kinship per se, but rather from the experience, while in the pursuit of other topics, of "discovering" at the local level the importance of kin ties exceeding the boundaries of the family or household.' In the pursuit of discovering Torajan livelihoods, I entered the realm of kinship-its puzzling terminology, meanings and boundaries-as a matter of course. Whereas most scholars in the field of social and cultural studies might have moved away from the study of kinship over recent decades, when considering Torajan society - as with many other both simple and complex societies-kinship is clearly a major dimension of social relations 
that cannot be neglected if one wants to understand livelihoods. Therefore, this section is an attempt to 'come to terms' with kinship in island Southeast Asia in general, and in South Sulawesi in particular. It does not present a full account of kinship systems as they have been reported in the specialized literature (mainly in anthropological writings). Rather, the discussion of kinship will centre on the objective of identifying its major characteristics in island Southeast Asia.

Before going into detail on this topic, let me provide a short history of the study of kinship in the region to provide background for the current stance. For a long period, the study of kinship in Southeast Asia was dominated by a concern with lineages and the construction of formal models of kinship terminologies (Kemp and Hüsken 1991; Waterson 1986). Until the 1950s, when kinship studies were still at the heart of the anthropological discipline, the focus was mainly on corporate groups as the main explanandum of social structure. This theory of society developed primarily out of fieldwork conducted by British social anthropologists in African countries. However, when social anthropologists entered the rural societies of Southeast Asia, the idea of the corporate group seemed to be of little help because such groups were relatively rare. Shelly Errington (1989:235) put this well:

In any case, accommodating the cluster of ideas around the corporate group (with its usually unstated conceptual baggage of the importance of descent to the formation of groups, the idea that kinship terminology is a distorted reflection of biological reality, etc., etc.) proved to be a strain when it came to Pacific societies, which often trace their 'kinship' relations 'cognatically' or 'bilaterally', where groupings often have vague or permeable boundaries, where recruitment to groupings is often not strictly along genealogical or descent lines, where indeed, 'kinship' (in the sense of a belief in shared body substance) sometimes does not feature in either the formation of groups or the reference of what we call 'kinship' terminology.

The relative absence of the characteristics of corporate groups in rural settlements of Southeast Asia and the new insights that came with increasing fieldwork in the region, produced a radical switch from an 'official' to a more 'practical' perspective on kinship, to use Bourdieu's terms (1977:37). In the second half of the twentieth century, this understanding developed, and it became generally accepted that the majority of Southeast Asia's population live in cognatic social environments, rather than in genealogically-determined corporate groups (Kemp and Hüsken 1991:1).

'Cognatic' or 'bilateral' are terms used to signify a type of descent that is non-unilineal, meaning that equivalent importance is ascribed to 
relations through men as well as through women. In the anthropological literature, cognatic kinship is often extended with a 'kindred' mode of organizing groupings. The concept of the kindred stems mainly from studies of indigenous Borneo societies (most notably, Leach 1950; Murdock 1960; Freeman 1961, 1970) and is, as such, mostly associated with 'simpler' societies (Kemp and Hüsken 1991:5). A kindred was defined as 'that cognatic category which embraces all of an individual's father's kin, and all of his (or her) mother's kin' and that spreads 'upwards and outwards from an individual standing at its centre, or base' (Freeman 1970:67). It is, thus, an ego-focus group of relatives based upon individual knowledge. Hence, depending on the point of view of the ego taken, it varies in constellation. Freeman (1960:71) concludes that:

Strictly speaking no two individuals have precisely the same kindred. However, if the relationships between themselves are excepted, and assuming they have not produced children of their own, the members of the same sibling group do have the same kindred. Looked in this way, a kindred is seen as radiating out bilaterally from the children of an elementary family to include all those persons to whom relationship can be traced consanguineally through both male and female links.

From this perspective, in many insular Southeast Asian societies, kinship can be understood as consisting of a set of full siblings that form a kindredcentre, a set of allies, or a kind of mini-grouping (Errington 1989:215). This coincides with the way many people of island Southeast Asia themselves often describe their social organization, namely in terms of plants, such as bamboo or coconut trees. Full siblings possess a common 'root' that makes up the 'clump' which is generally hidden from view. Thus, although the various siblings visualized as trunks might seem to be separate trees with their own trunk, the opposite is true; they are all of the same plant with a common shared trunk. Therefore, in South Sulawesi (as in many other societies found among the Southeast Asian archipelagoes) siblings are considered to be a single entity and expected to act accordingly. ${ }^{14}$ In this way, '[f]irst-degree siblings (first cousins in our terms) are siblings whose

14 In comparing kinship and relation terminology, Shelly Errington (1989:207) distinguishes two regions in island Southeast Asia which comprise comparative kinship characteristics: 'Eastern Indonesia' and the Centrist Archipelago. She refers to the Centrist Archipelago as the region that includes those societies which are located on the swath of islands rimming mainland Southeast Asia, stretching from the Malay peninsula through Borneo, dipping into Java, Sulawesi, the Moluccas, and Mindanao, Luzon, the Visayas, and other Philippine islands. Eastern Indonesia is considered as the region that includes all Indonesian islands east of Bali, including Lombok, Sumba, Sumbawa, Flores, Timor and Ambon. 
common source or root is two generational layers removed from themselves (i.e. in the grandparental layer); second-degree siblings' common root is three layers removed' (Errington 1989:215). As full siblings stem from exactly the same parents in the layer above them, they are considered as full equivalents in whatever is passed on (noble blood, land, ornaments, and the like) from the 'roots' to the descendants. It follows that many people in these societies consider themselves to be as closely related to the full siblings of their parents and grandparents as to their own parents and grandparents.

Thus, by embodying forebears in layers rather than in lines, these cognatic relationship systems lead quickly to an enormous number of forebears for each individual in them. Not surprisingly, therefore, people trace themselves 'not from forebears but to forebears' in these societies (Errington 1989:216). In doing so, they often trace themselves back to the most important and highly-valued forebear. This upward-looking is thus often blurred, or coloured, by 'genealogical amnesia' as the Geertzes termed it (1975:85). Chabot (1950) had already shown in his study on a Makassarese and Buginese community in South Sulawesi that genealogical ties, or better the strategic use of them, are of particular relevance in understanding the origins and practice of political power. The same is true of the ritual and religious dimensions. By introducing the concept of 'worship community' Chabot shows that it is ancestor worship that makes up one of the most important indigenous concepts in defining social cohesion. In other words, the 'individual choice of genealogy', at least to some extent, can be seen as an intrinsic feature of such 'loosely structured' social systems that provides individuals with options when it comes to social and religious alliance (Rössler and Röttger-Rössler 1996:34).

On the basis of Thai and Malay kinship systems, Jeremy Kemp (1991:93) argues that genealogical connection is, in practice, just one possible characteristic of 'the relationship between those who speak of and treat one another as kin'. He uses the term 'affinity' to distinguish those people who are in fact not kin but are called upon in the name of kinship from those who are kin through descent. He argues that those related through affinity should not be placed within the kindred but, insofar as they become equated with genealogical kin, they can and do form part of what he calls the 'effective kindred': all those individuals who are called upon in the name of kinship (Kemp 1991:93). Because of these seemingly fluid and permeable kinship boundaries and 'loose structuredness' in many Southeast Asian societies, Kemp (1991) maintains that the focus should shift away from the existence and functions of descent groups. He proposes 
repudiation of the observer's externally derived, inherently group-minded formulations of kinship and, instead, study of 'the patterning of dyadic relations and from there move to an examination of the extent to which group formation does or does not take place' (Kemp 1991:95). In this perspective, he sees kinship as an ideology with the institutions that often go by that name. He suggests that kinship should be understood as the value it embodies, meaning 'the axiom of amity', to specify 'the rule of prescriptive altruism' (Fortes 1970 in Kemp 1991:103). 'In kinship we thus have a field of social obligation where the individual actor is supposed to perform according to normative expectations of right and wrong irrespective of whether he or she actually likes the person concerned, or whether fulfilment of these obligations serves perceptions of self-interest' (Kemp 1984:60).

Placing relations within the arena of kinship can thus be an effective means of manipulation. 'Kinship is an ideological discourse at the participants' level where it serves to create, mediate, manipulate, and express social relations' (Kemp 1991:104). Kinship terms give one a social identity and mark a number of qualities; they are a form of coded references to certain qualities that may already exist in a relationship or indicate an attempt to imbue it with them. The resort to kinship terms may not be just an appropriate validation of an existing relationship but part of the tactics used in developing and consolidating close relations. While there is no suggestion that the positive idiom of kinship is always translated into action, ${ }^{15}$ in many highly complex societies, kinship remains the dominant idiom for handling close relations. ${ }^{16}$ Thus, rather than viewing kinship from a structural or corporatist perspective, kinship terms and more general references to kinship reveal the web of interpersonal relations linking all residents of a village community in many island Southeast Asian societies (Kemp 1991:104; Kemp and Hüsken 1991). We have to place Torajan livelihoods in these types of relationships.

\section{Beyond Kinship: House Societies}

An increasing dissatisfaction with the analytical vocabulary of kinship for explaining social organization, together with the concomitant recognition of the heuristic importance of indigenous terms and concepts in the 1970s

\footnotetext{
15 As Kemp (1991) stresses, there are plenty of examples of kin cheating on one another and failing to meet their obligations.

16 See for example Waterson 1986, 1991; and Waterson 2009 for Tana Toraja.
} 
and 1980 s, led to a great interest in the 'house' as an important analytical concept to characterize island Southeast Asian groupings (Gillespie 2000; Waterson 1986, 1991, 2009). The general recognition of the 'house' as much more than a physical structure followed upon the introduction of the notion of house as a type of social structure by Lévi-Strauss $(1983,1987)$. In some brief sketches in which he compares the house of the Kwakiutl on the northwest coast of North America with that of the noble houses of feudal Europe, while alluding to some other societies in Southeast Asia and Polynesia, Lévi-Strauss (1983:174) defined the house as: 'a corporate body holding an estate made up of both material and immaterial wealth, which perpetuates itself through the transmission of its name, its goods and its titles down a real or imaginary line, considered legitimate as long as this continuity can express itself in the language of kinship or of affinity and, most often, of both'. Lévi-Strauss termed societies in which this idea of houses as the foci of kin or kinship organization predominated 'house societies'.

This idea of houses turned the earlier classificatory assumptions on kinship completely upside down and seemed especially useful for those trying to explain social organizations in Southeast Asia (Gillespie 2000:7). As Waterson (1986) puts it, 'where South-East Asian societies may confuse the outsider by their apparent lack of boundaries, the house as an institution shaping identities and relationships may provide a key to the understanding of these systems.' In fact, from the body of literature on house societies in Southeast Asia in general and Indonesia specifically, it appears that houses fulfil a key function in anchoring people in social space and linking them across time. The temporal dimension points to what Waterson (1991) calls 'the living house': the house as an embodiment of the continuity of a group of kin over several generations. Houses have a 'life history' and a biography that are intertwined with those of their human members and, because of that, anchor their members to a place and connect them through it to their ancestors (Waterson 2000:181-2). Or, as Gillespie (2000:3) phrases it: 'the time depth inherent in the ideology of the house or its valued heirlooms that serves to embody a collective memory about the past, [is] a reference to origins that often forms a salient bond uniting members'.

The function of a house as a spatial locus of a group of people forms the basis for the social dimension. This idea contrasts with the classificatory assumptions of clans and lineages since houses have no singular form of affiliation. This means that '[d]escent and inheritance may flow through either or both parents depending on circumstances; endogamy 
and exogamy may coexist; postmarital residence is contingent on a number of factors; and marriage patterns, exchange relations, co-residence, or shared labor may be the primary determinants of social relationships, rather than their outcomes' (Gillespie 2000:7). House membership is very variable and differs between and sometimes even within societies: in some societies individuals belong to a single house; in others they might be considered as members of more than one house; and in others again they might not be a member of any house at all.

Hierarchy is often prevalent in house societies, both in the way houses are positioned to one another and within the members' group of individual houses. Given the 'plant-branching principle' of kin that prevails in many parts of Southeast Asia, it is not surprising that status and power are often concentrated in the older origin-houses of these societies. Someone's position in house societies is expressed in relation to a particular house (high- or low-ranking) and, as such, 'it is the language of kinship or of affinity, or most often, of both that makes the house what it is" (Gillespie 2000:8). Usually, only a few groups are capable of strategically utilizing relationships (manifested as kin and marital relationships) and sustaining them over generations. Where most groups are unable to do so, this forms the foundation for a social hierarchy which is 'experienced as considerable differences in prestige, wealth, and ritual, and political power, both within and between houses' (Gillespie 2000:8-9). Waterson (1991:142), therefore, argues that kinship and ranking systems ${ }^{17}$ are closely intertwined with the house. The completion of prestigious and impressive projects, such as houses, temporary ritual structures and huge stone tombs or ornaments, demands the cooperation of a large group of (kin)people associated with the house, and also the existence of a social ranking system within society that gives the members of the aristocracy the power and the wealth to undertake such projects. Houses further offer the aristocracy a clearly visible means of displaying their wealth, status and power. This can be done through the design of the house, its size, its distinctive shape and its fine ornamentation. The construction of such enduring signs of prestige usually involves expensive ceremonies and, when finished, it becomes the site of rituals (Waterson 1991:140). In conclusion, a perspective on the house makes it possible to see all the various and differentiating kinship systems

17 Following Hefner (1990:26) class as used throughout this book refers to 'aggregates of individuals who are similarly situated relative to control of the means of production and other market resources'. This implies that class is distinguished from social stratification, or the evaluative system of ranking used by members of society in attributing prestige. 
as allowable variants, all of which have the house as an important focus of social organization (Waterson 1991:139).

\section{Moving beyond Local Boundaries}

Any sociological analysis of why and how things happen will need to take account of where (and when) they happen. ${ }^{18}$

I have been arguing above that livelihood styles are embedded in a particular locality or place. This does not necessary imply that the deployment of different practices occurs only in one specific locality. Instead, as the stories in the introduction show, some livelihood practices are spread over multiple locations, transcending local, regional as well as national boundaries. Due to their long history of migration, most Torajans possess a large web of social relations spread over a number of places. The Torajan networks that reach out in the wider realm of social space link migrants both to their places of origin and to their kin, co-villagers, co-ethnics or compatriots living in widely dispersed locations all over Indonesia and often beyond. Improved communication and transportation increases opportunities for migrants to maintain ties with network members in other places. These networks of people and places are bound together through 'collective memories' and images of a common place of origin, and possibly of places of migration, and create the sense of a collective identity that differentiates 'us' from 'them' (Long 2000:198).

The increasing importance of these so-called translocal and/or transnational networks in shaping Torajan livelihood decisions and practices forces me to use an analysis that goes beyond livelihoods as simply being created, negotiated, and fought for principally in one locality (Mazzucato 2004:135). As the earlier conceptions of international migration are simply incapable of capturing the full complexities of multiplicity and translocality, I now turn to some theoretical ideas that stem from the literature on transnationalism. ${ }^{19}$ These theories help me avoid looking at livelihoods as sedentary lives and solely as the natural state of society, and to move 'beyond simplistic dichotomies of migrants as either moving for economic or political reasons' (Mazzucato 2004:136). Although it is important to

\footnotetext{
18 Cited by P. Saunders 1989: 218.

19 Most notably: Glick-Schiller et al. 1992, 1995; Clifford 1994; Appadurai 1995; Marcus 1998; Portes 1995, 1999; Vertovec 1999; Faist 1998, 2000; Mazzucato 2004.
} 
acknowledge 'the open and porous boundaries of places as well as the myriad interlinkages and interdependencies among places, ${ }^{20}$ one cannot exclude from any consideration the places themselves that serve as anchoring points of the translocal networks. In fact, translocal networks are largely place-based and place-nourished as Ma (2003:10) emphasizes while referring to the Chinese diaspora. In her study on the habitus of Torajans, Waterson (2002:330) notes that the Torajan traditional religion, with its elaborated ritual life (especially funerals and house ceremonies), is highly interwoven with the local landscape and activities, and is not translated easily to other contexts.

This is one reason why migrants continue to show a remarkable loyalty to their homeland, often returning long distances to be present at rituals. The fact that some rites continue to be so prominent in Toraja life, even in a Christianized form, gives some indication, too, of the great social significance of rituals for the maintenance of kin relationships and the building of local political careers. Likewise it is said that an origin-house built in the traditional style would make little sense outside of Toraja itself and could never really become a tongkonan. Still, attachment to places and houses of origin remains sufficiently strong that many emigrant Toraja are prepared to make financial contributions to the rebuilding of origin-houses in which they will never reside.

Considering the importance of selected places as anchoring points for translocal Torajan networks, I start this section with an exposition of the concept of place. Or, in other words, with an analysis that pays attention to the 'local' before moving to the 'translocal' to prevent an over-emphasis on either one or the other.

\section{'A Sense of Place'}

Place is the first of all beings, since everything that exists is in a place and cannot exist without a place. ${ }^{21}$

The notion of place has a long history and embodies a multiplicity of meanings and connotations that have resulted in a large body of literature on the concept. Place 'can raise an image of one's place in the world, of the reputedly...deep meanings of "a place called home" or, with much greater intimations of mobility and agility, can be used in the context of

20 Massey 1997, Perose 1993, and Young 1990 in Johnston et al. 2000:583.

21 Archytas, as cited by Simplicius, 'Commentary on Aristotle's Categories', in Basso 1996:3. 
discussions of positionality' (Massey 1994:1). In the following, I pull out a few threads from the enormous complexity of this field in order to pave the way for a particular way of thinking about place-one that is needed for a better understanding of place or locality in Tana Toraja. The concept of place is frequently used in the social science literature to casually describe settings, but it is rarely defined or problematized (Low and Lawrence-Zúñiga 2003:16). In reviewing the large body of social science literature on 'place' or 'locality', one can identify three major ways of looking at it, or giving it meaning. ${ }^{22}$

The first meaning of place is 'as a framing device used "objectively" to bring people into view” (Low and Lawrence-Zúñiga 2003:16). In this perspective, locality can be seen as purely descriptive, as the background setting. This view refers to either a geographical or an administrative unit. Although the boundaries may vary, places are considered as bounded sites with a certain unity between the place and the people that embody it. The perspective taken depends on the starting point: 'if an administrative unit is taken as a starting point, its characteristics may not be limited to that region. If however, a regional unit is defined on the basis of common features, like economic structure, population density or landscape and ecological aspects, locality acquires the meaning of territorial uniqueness' (De Haan 1997:159). In both perspectives, locality is perceived as a concrete, place-specific outcome of larger socio-economic, political and cultural processes.

The second way in which the concept of place is used is as a 'socially constructed place', as Rodman (1992) puts it. Or, in other words, place refers to the meaning people attribute to their surroundings. Rodman criticizes the usual anthropological conceptions of place that provide 'taken-for-granted settings' to situate ethnographic descriptions (Low and Lawrence-Zúñiga 2003:15). Rather than using place analytically as a metaphor, or reduced to a locale that imprisons natives, Rodman argues that places should be considered as socially constructed by the people who live in them and know them; they are 'politicized, culturally relative, historically specific, local and multiple constructions' (Rodman in Lawrence-Zúñiga 2003:15). As such, 'Place can have a unique reality for each inhabitant, and while the meanings may be shared with others, the views of place are often likely to be competing, and contested in practice'.

22 While not implying that the concepts of 'place' and 'locality' are given identical meanings or connotations by all authors, for the purpose of this study I use them interchangeably. 
A socially constructed place, thus refers to the idea that place is a particular articulation of social relations at a particular moment within networks of social relations and understandings (Massey 1994:5). Massey point out that 'the particular mix of social relations which are thus part of what defines the uniqueness of any place is by no means all included within that place itself. Importantly, it includes relations which stretch beyond - the global as part of what constitutes the local, the outside as part of the inside'. In contrast to the first notion of 'bounded' places, this perspective views place as open and porous, and not constructed by placing boundaries around it and defining its identity through counterposition to the other. Rather, places are constructed 'precisely (in part) through the specificity of the mix of links and interconnections to that "beyond"' (Massey 1994:5).

Anthony Giddens (in: Massey 1994:6) argues that this separation of place from social space is a consequence of modernity:

In premodern societies, space and place largely coincided, since the spatial dimensions of social life are, for most of the population...dominated by 'presence'-by localized activity...Modernity increasingly tears space away from place by fostering relations between 'absent' others, locationally distant from any given situation of face-to-face interaction. In conditions of modernity...locales are thoroughly penetrated by and shaped in terms of social influences quite distant from them.

Although Giddens might be right to argue that space is increasingly distinct from place, the erosion of this supposedly natural connection between people and places is not necessarily modern. Nor has it led to the modernist spectre of global cultural homogenization (see Clifford 1988 in: Gupta and Ferguson 2002:69).

This latter point brings me to the third perspective on place which also developed as a critique on places as a bounded whole, but this time from an anthropological standpoint. Triggered by Benedict Anderson's Imagined Communities (1983), a field of study emerged that questioned the idea that specific cultural features are tied to a given population inhabiting a particular locality (Mazzucato 2004:140). Gupta and Ferguson (2002:69) state that no matter how persistent 'cultures' and 'peoples' may be,

they cease to be plausibly identifiable as spots on the map. But the irony (...) is that as actual places and localities become ever more blurred and indeterminate, ideas of culturally and ethnically distinct places become perhaps even more salient. It is here that it becomes most visible how imagined communities (Anderson 1983) come to be attached to imagined places, as displaced peoples cluster around remembered or imagined homelands, 
places, or communities in a world that seems increasingly to deny such firm territorialized anchors in their actuality.

Interestingly, Gupta and Ferguson (2002:75) point to the relationship between space and place. Space is:

Imagined (but not imaginary) as a way to explore the mechanisms through which such conceptual processes of place making meet the changing global economic and political conditions of lived spaces (ibid. 70).

Since the objects of social scientific research can no longer be conceived as automatically and naturally anchored in social space, they suggest paying special attention to the way spaces and places are made, imagined, contested and enforced.

\section{A Conception of Transnationalism}

From the introductory chapter it seems that the Torajan social space consists of a continuous flow of people, goods, money and ideas that transgress local and even national borders. Given that the old conceptions of international migration, 'conceiving migration in terms of one or more discrete moves' (Mazzucato 2004:131), are incapable of capturing livelihoods that are being composed in more than one locality, I turn to some theoretical ideas that stem from the literature on transnationalism. ${ }^{23}$ The concept of transnationalism made its appearance in the early $1990 \mathrm{~s}$ as an alternative to the studies of migration. '[A]dvances in information and communication technology, cheaper air travel, and the modern capitalist production relations of the past half century have given rise to new... forms of human mobility which has seemingly connected disparate locations of the globe' (Mazzucato et al. 2006:1047). Against this background scholars of transnationalism ${ }^{24}$ point to the idea that new times and new socio-historical circumstances demands a new theoretical paradigm (Kivisto 2001:554). Subsequently, a great body of literature has emerged on transnationalism in which the definitions of the concept reflect the disciplinary backgrounds of the scholars it has attracted (Mazzucato 2004:131).

For the purpose of this study, I will adopt the widely-used conceptualization by Glick-Schiller et al. (1992:7), 'the process by which immigrants forge and sustain multi-stranded social relations that link together their societies of origin and settlement.' They designate immigrants who build such social fields as 'transmigrants' (Glick-Schiller et al. 1992:1-2) and say,

\footnotetext{
23 For a detailed overview of migration studies, see De Haas (2005).

24 Most notably Glick-Schiller et al. 1992, 1995; Portes 1998, 1999; Vertovec 1999; Faist 1998, 2000.
} 
'Transmigrants develop and maintain multiple relations-familial, economic, social, organizational, religious, and political — that span borders. Transmigrants take actions, make decisions, and feel concerns, and develop identities within social networks that connect them to two or more societies simultaneously'. In this definition, the emphasis is heavily on the dynamic process of building transmigrant 'social fields', labelled transnational social spaces by Faist (2000:210-1). Scholars of transnationalism thus question 'notions of space in which social, economic and cultural phenomena are assumed to overlap perfectly in one geographic area, usually a village, region, agro-ecological zone or nation" (Mazzucato et al. 2006:1047-8). Rather, they emphasize the "crossing or transcending of boundaries through the flow of ideas, cultural images (Appadurai's (1996) ethno-space, media space, etc.), and people and goods that contribute to the constitution of new spaces' (Mazzucato 2004:133). Moreover, they shift the focus away from 'the economic and political reasons of why migrants leave, to the connections that migrants entertain with their relatives and community members in the homeland and across the diaspora' (Mazzucato 2004:137).

Under the term 'diaspora', another related conceptual framework has surfaced which has generated a vast amount of literature (see for example Clifford 1994; Watson 2004; Tsagarousianou 2004). This other approach has much in common with transnationalism, and the main difference is in the extent to which people's roots are stressed. The word 'diaspora' has been in use for centuries, and in its original meaning 'the diaspora experience was related to traumatic occurrences, forceful dispersal and the not feeling at home of diasporic people in their new places of settlement.'. Over the years, the concept has moved increasingly away from the forced character of the movement and has been used so often that it has almost replaced the term 'migration' (Skeldon 2003). For the purpose of this study, it is not useful to elaborate the term 'diaspora' further, but what I would like to stress is that the concept of diaspora is useful for pointing to the transnational migrant community within a transnational social space (that includes non-migrants).

Let me make one final important comment on the concept of transnationalism. Many migrants live in places thousands of kilometres from their home village. Notwithstanding these distances, they still might not have crossed national borders and are, as such, not technically transnational migrants. One can think of large countries such as China, India and

25 Horst 2003:35. For a more detailed explanation on the term 'diaspora', see also Horst 2003:35. 
Indonesia that have many ethnic groups, each with its own culture, religion, language and so on. Precisely because of the size of these countries and the differentiated nature of societies and contexts, I consider the ideas in the literature on transnationalism appropriate for analyzing networks that do not transgress official established national borders, but only local and provincial borders within these countries. I will call these networks 'translocal', to differentiate them from 'transnational' but, broadly speaking, they have the same theoretical foundation.

\section{Where Do We Go from Here?}

In this chapter, I have attempted to construct a theoretical framework for the analysis of the complex reality I encountered during my fieldwork. In so doing, the aim is to find a way out of the paradox that is central to this study as well as to contribute to the theoretical discussions within livelihood studies. After a short explanation of the analytical shortcomings I perceive within the existing livelihoods models in understanding the full complexities of everyday Torajan life, I conclude that the analysis should not focus on either actor or structure, but include both, go beyond a single locality, and include the historical and cultural dimensions as well as the social space in which livelihoods are created, enhanced and secured. Based on either Bourdieu's and Giddens's accounts of lifestyle, I introduce the term 'livelihood style' to arrive at such an analysis. Livelihood style is defined here as a recognizable and coherent pattern of practices that results from an actor's conscious and unconscious objectives in establishing, maintaining, and enhancing a living in interaction (both in a cooperative and conflicting manner) with other actors over time, and within the framework of status systems, cultural ideals and geographical space and place(s). The concept differs from earlier approaches to livelihoods in that livelihood styles do not explain the vulnerability of people's lives solely by looking at assets, capabilities and activities of agents, but also encompasses people's perspectives or objectives in obtaining a living and the more cultural aspects and contexts that shape these aspects.

The term 'style' emphasizes the fact that people do not opt for particular practices in a social vacuum, but rather that they are part of particular groups or, more specifically, networks of social relations. Through social relationships, people's styles are positioned in the social world. To understand why people choose particular scenarios or styles and how they come about, it is thus necessary to take into account the social dimension or social space. Given this, I have elaborated on the various aspects that make 
up social space in general and tried to obtain some analytical handles for mapping the Torajan social space in particular. In so doing, I discuss the concept of social relations and networks that make up the general social space, with an emphasis on kinship and houses since these appeared to be the most important factors among the many that form the basis of the structure of Torajan relationships and networks.

Next to the social spaces, livelihood styles are embedded in a particular locality or place. In reality, these places serve as anchoring points for the translocal social world that shape Torajan livelihood decisions and practices. The analysis outlined in this chapter, therefore, pays attention to both the local as well as the translocal. The conceptualization of translocality is mainly inspired by theories on transnationalism.

The theoretical concepts outlined in this chapter will only make sense when we look at concrete cases. In the following chapters, I outline the details of the various structural (political, cultural and economic) layers that make up the Torajan world, and the range of scenarios that people have at their disposal to make a living. Together with the Torajan migrant world (the translocal community) and homeland (place), these layers shape the various livelihood styles that will be outlined in Chapter 8 . 